\title{
Pathogenesis of Oral Candidiasis
}

Amisha A Shah ${ }^{1}$, Aamera $\mathrm{M}^{2}$, Mrinal Mayank ${ }^{3}$, Dinraj Kulkarni ${ }^{4}$

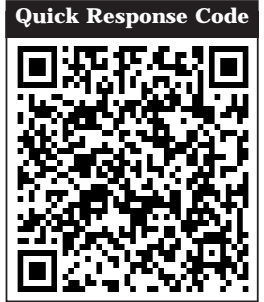

doi : $10.5866 / 2014.621529$

1,2,3\&4 Department of Oral and Maxillofacial Pathology, M. A. Rangoonwala College of Dental Sciences \& Research Centre, Pune

\section{Article Info:}

Received: J anuary 9, 2014

Review Completed: February 10, 2014

Accepted: March 8, 2014

Available Online: J uly, 2014 (www.nacd.in)

(c) NAD, 2014 - All rights reserved

Email for correspondence:

mulla.aamera@gmail.com

\begin{abstract}
:
Candida albicans is considered as commensal oral flora and is one of the most common fungal pathogens in the oral cavity causing severe opportunistic infections. They are dimorphic in nature, existing in the relatively innocuous yeast form and the invasive hyphal form which is responsible for the pathogenesis of Candidal infection by promoting formation of fungal biofims and tissue penetration. The organism al so exhi bits various other virulence factors which also contribute to the pathogenecity of the organism depending on the host response. This paper presents a review on the current knowledge of candida infection, addressing the issue of various virulence factors and their interaction with the host environment resulting in oral candidal infection.
\end{abstract}

Key words: Candidia albicans, hyphae, virulence factors, adhesions

\section{NTRODUCTION}

Candida albicans, a commensal oral flora, is considered to be the primary etiological agent for oral candidiasis. Other species of Candida such as C. tropicalis, C. parapsilosis, C. krusei, C. guilliermondii etc may also be found intraorally but rarely cause disease. ${ }^{1}$ These organisms colonize at multiple mucosal sites leading to infections ranging from superficial "oral thrush" to disseminated systemic lesions in immunocompromised individuals if the organisms are released into the bloodstream. ${ }^{2}$ The spectrum of oral lesions of candidiasis varies from large white plaques of pseudomembranous candidiasis on the buccal mucosa to erythematous lesions of chronic atrophic candidiasis on the palate. ${ }^{3}$

\section{Candida albicans: A Dimorphic Fungus}

Since C. al bicans exists in the yeast form as well as in the hyphal form, they can be considered as dimporphic. However some authors consider it to be polymorphic exhibiting several different morphological forms including budding yeast cells (blastospores, blastoconidia), pseudohyphae (elongatged yeast cells that appear as filamentous cell chains), true hyphae and chlamydospores., 5

\section{Indian Journal of Dental Advancements}

Journal homepage: www. nacd. in 
A blastosporeis a unicellular form of the fungus that divides by budding. A hypha is a long microscopic tube which comprises multiple fungal cell units divided by septa. Germ tube formation is theinitial stage in yeast - hyphal transition. Mitosis takes place within the extending hypha and septae are formed at intervals within the hyphae. The entirefungal cellular aggregateincluding branching hyphae is termed as mycelium. ${ }^{6}$

Yeast - hyphal transformation takes place when temperature and $\mathrm{pH}$ alterations occur within the host. When the ambient host temperature is bel ow $33^{\circ} \mathrm{C}$ and $\mathrm{pH}$ turns acidic (average $\mathrm{pH}=4$ ), the growth of yeast form is favored. Hyphal growth occurs when the temperature increases to around $37^{\circ} \mathrm{C}$ and $\mathrm{pH}$ turns neutral. Between theses temperatures and $\mathrm{pH}$ values, pseudohyphae may be produced. $^{3}$

These different morphologies of $\mathrm{C}$. al bicans have distinct roles in the course of infection. Saville et.al 2003 stated that the yeast form is important for dissemination through the bloodstream and this was supported by Bendel et al 2003.7,8 The yeast form also adheres to endothelial surfaces leading to colonization. ${ }^{9}$ The filamentous form is invasive and thus better adapted for invasion through the host epithelium. ${ }^{10}$ It has also been shown that the hyphal forms are more resistant to phagocytosis due to their morphology. ${ }^{4}$

\section{Pathogenecity of Candida}

Although Candida is seen as a commensal oral flora, the occurance of candidiasis occurs in sel ective individuals predominantly those with compromised immune response or those with prostheses coupled with poor oral hygiene habits etc. The conversion of this relatively innocuous commensal organism to the pathogenic stage ther efore depends on an interaction between the organisms with the host environment and the resident bacteria present and can be triggered by serum, proline, $\mathrm{N}$-acetyl glucosamine, and different carbon sources etc. ${ }^{2,4}$

\section{Role of Resident Bacteria}

The resident oral bacteria like S. mutans and S. gordonii are capable of promoting or attenuating the hyphal growth either by physical interactions or chemical signaling via production of quorum sensing molecules like farnesol and tyresol which are negative and positive regulators of morphogenesis respectively. ${ }^{4}$
Fuqua et al 1994 first coined the term "quorum sensing" to describe the co operative behavior of bacterial cells that takes place only when a certain cell population density threshold is reached. ${ }^{11}$

Gray et al 1994, Henseet al 2007, Nealson 1997, referred to quorum sensing as autoinduction - a process by which individual cells release small diffusible molecules into their environment and these molecules are sensed by all cells in the population. ${ }^{12-14}$ When high cell density is reached, these auto indicing molecules accumulate above a certain threshold level, activating and/or repressing certain genes which subsequently induces a complex cellular behavior like secretion of hydrolytic enzymes, bioluminescence, plasmid transfer, antibiotic synthesis, biofilm development and morphological switches. ${ }^{15-21}$

\section{Virulence Factors Expressed By C. albicans}

In order to overcome host defenses and cause disease in an individual, various virulence factors are expressed by $\mathrm{C}$. al bicans. These depend on type of infection, site and stage of infection and nature of host response. Amongst the various virulence factors, hyphal formation phenotypic switching, adherenceand production of extracellular hydrolytic enzymes have been most widely studied in recent years. ${ }^{22}$

\section{Role of Hyphae in Pathogenesis of Candida}

Formation of hyphae results in the devel opment of fungal biofilms which promotes adhesion to biotic or abiotic surfaces and tissue penetration leading to infection. These biofilms are relatively resistant to treatment with anti fungal agents and thus pose clinical problems.

\section{Physical properties of Hyphae}

\section{Morphogenesis \& Morphology:}

Morphogenesis exposes surface mol ecules which are responsible for alerting the immune system to the presence of the pathogen. This is mediated by detection of pathogen associated molecular patterns (PAMP's) and is microbe derived molecules that are recognized as non host by phagocytes. PAMP's which are derived from fungi include cell wall polysaccharides (â glucans, chitin phosphomannan), fungal surface proteins, secreted fungal enzymes and their breakdown products and ATP released during host cell lysis. ${ }^{23-27}$ 


\section{Grows in more than one morphological form - Dimorphic} HYPHAE

\begin{tabular}{|l|c|c|c|}
\hline \multicolumn{4}{c}{ YEAST } \\
\hline & \multicolumn{3}{|c|}{ Factors influencing dimoprhism } \\
\cline { 2 - 5 } & 7 & $\mathrm{pH}$ & 4 \\
\hline & $37^{\circ} \mathrm{C}$ & Temperature & $<30^{\circ} \mathrm{C}$ \\
\hline
\end{tabular}

Stage 1: Colonization Epithelial adhesion Nutrient Acquisition

Stage2:Superficial Infection

Epithelial penetration Degradation of Host Proteins

Stage3: Deep seated Infection Tissue penetration vascular invasion Immune evasion or escape

Stage4: Disseminated Infection

Endothelial Adhesion Infection of other host tissues Activation of coagulation cascade
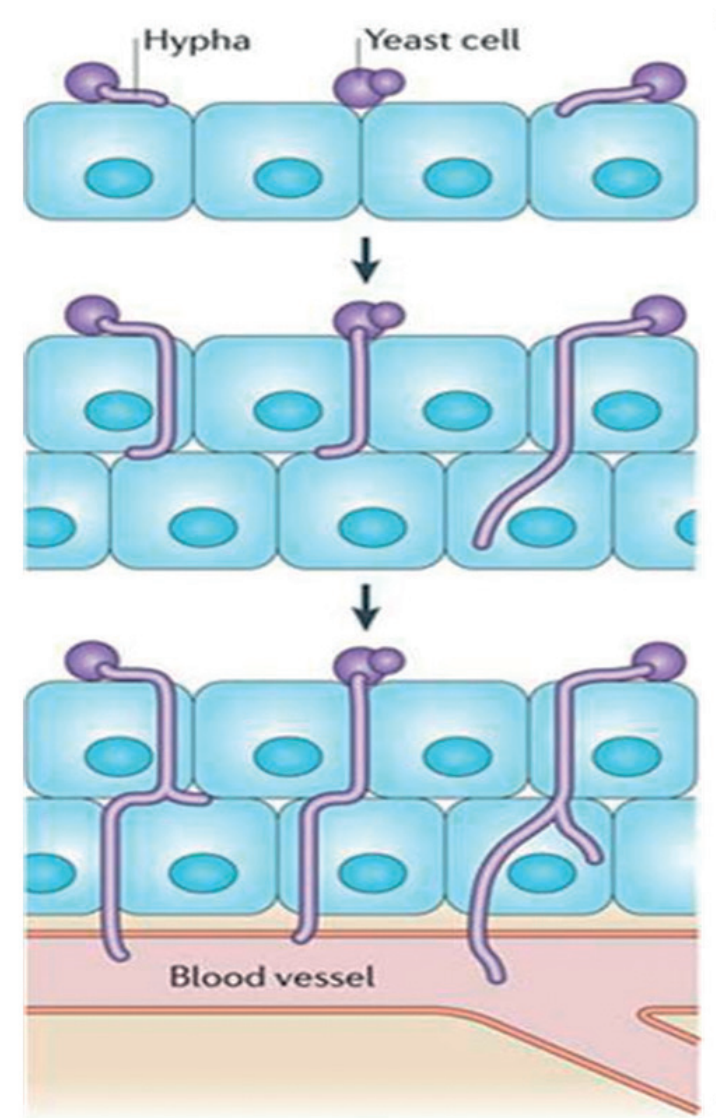

$\downarrow$

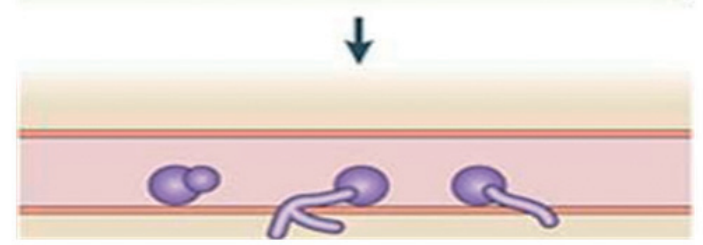

Virulence Factors:

Hypha Formation Adhesins Hydrolytic Enzymes

Hypha Formation Hydrolytic Enzymes

Hypha Formation Hydrolytic Enzymes Host mimicry? Immunomodulators?

Hypha Formation Adhesins Hydrolytic Enzymes Phenotypic Switching? Antioxidants? Immunomodulators? 
Dectin 1 is a C - type lectin involved in recognition of â glucans found in cell walls of fungi resulting in production of cytokines which activate a group of proteins called the inflammasome, which is expressed within mucosal macrophages and dendritic cells. ${ }^{28}$ This inflammasome in turn releases interleukin IL-1â which recruits $T$ cells and neutrophils which form the main line of defense against C.al bicans via phagocytosis and deployment of neutrophil extracellular traps (NET's). ${ }^{29-32}$ Thus morphogenesis is a virulence factor if host immunity is compromised.

\section{Direction Of Hyphal Tip}

Directional growth is a function of polarized cells like fungal hyphae. The hyphae of $\mathrm{C}$. albicans respond to various asymmetric environmental signals by altering their axes of growth in a regulated method. ${ }^{33}$

Thigmotropism is the property by which hyphae of $C$. albicans change their direction of growth in response to alterations in surface topography. On hard surfaces or liquid media, the trajectory of hyphal growth is linear, while on semi-solid surfaces the hyphal tips grow in an oscillatory manner to form regular two dimensional sinusoidal curves and three dimensional helices. ${ }^{34}$ Galvanotropism is the property by which hyphae respond when exposed to electric field. The presence of cal cium ions regulates these responses. The hyphal tip thus controls the direction of new growth in response to the environment and helps steer the hyphae towards the nutrients and also around obstacles. ${ }^{35}$

\section{Force and Adhesion}

Along with directional growth, the hyphae also need mechanical forces to push the surrounding matrix in order to penetrate physical barriers and to steer around obstacles and towards nutrients. Candidal hyphae exhibit both these properties within the host. In order to exert adequate mechanical force for penetration of hyphae, the organism needs to adhere to the host surface.

Hwp 1 is a well known cell surface protein of C. albicans expressed only on the hyphal form. ${ }^{36}$ The protein Hwplp is a substrate for host transglutaminases and thus it can be covalently cross linked to the surface of host tissue and result in adhesion of organism to the host. ${ }^{37}$ This was supported by the findings who conducted a study and inferred that Hwpl mutants are defective in adhesion to epithelial cells and fail to cause oral or esophageal lesions in immunodeficient mice. ${ }^{38}$ Thus suggesting that expression of Hwplp adhesion on the surface of hyphae is important for epithelial penetration.

Efglp dependent expression of appropriate adhesion allows tight adherence of $\mathrm{C}$. al bicans cells to epithelial surface, aiding the application of force by hyphae. Thus, components of the hyphal regulon act together to produce characteristic invasive lesions of mucosal candidiasis. Generation of adequate adhesion by developing hyphae is time dependent. Thus the number of cross links formed with the host increases with the hyphal length. ${ }^{39}$

\section{Stages in Candidal Infection}

The progress of candidiasis can be divided into stages depending on the extent of invasion.

\section{Stage 1: Colonization}

Colonization of the oral cavity by $C$. albicans can be defined as the acquisition and maintenance of a stable population of $C$. al bi cans cells which does not giveriseto clinical disease. Col onization depends on the rate acquisition- that is, the rate at which yeast cells enter the oral cavity - growth, and removal of cells from the mouth by swallowing and oral hygiene. To simplify this explanation, if the rate of removal is greater than that of acquisition and growth, clearance will take place. If the rate of removal is the same as that of acquisition and growth then there will be colonization. If the rate is lower and there is tissue damage, it will lead to candidiasis.

The presentation of candidiasis will depend on the tissue col onized, the virulence factors expressed by the Candida cells, and the host response. Thus, colonization depends on several factors like the acquisition or entry of cells into the oral cavity, the attachment and growth of those cells, the penetration of tissues, and the removal of cells from the oral cavity. ${ }^{40}$

\section{Stage 2: Superficial Infection by formation of Fungal Biofilm}

Mucosal infections by C. albicans are caused primarily dueto formation of bi ofilms where plaques formed by over-proliferation of adhered cells to oral epithelium are easily visible. After colonization of the yeast cells, a phase of cell filamentation and proliferation begins which results in formation of multiple layers of sessile cells of different 
morphologies including pseudohyphal and hyphal cells. This is followed by maturation which results in a complex network of cells embedded in an extracellular polymeric matrix composed of carbohydrates, proteins, hexosamine, phosphorus and uronic acid. ${ }^{41}$

There is also some evidence that host glycoproteins, nucleic acids and cells like neutrophils may also hel $p$ in maturity of the matrix in particular on the mucosal sites. ${ }^{42-44} \mathrm{Hyphal}$ formation is not essential for the formation of maintenance of biofilms, however, the tangle of hyphal filaments strengthens the structure of the biofilm. ${ }^{45}$

\section{Stage 3: Tissue penetration}

Hyphae consist of a chain of el ongated cells that expand at the apex of the cell tip. ${ }^{46}$ When cells divide, the mother and daughter cells remain confined to the particular site and thus compete for nutrients. Hyphal formation allows new cells to be produces subsequently by expansion at the tip. The bulk of the cytosol of the mother cell is pushed forward by turgor pressurealong with expansion of the vacuoles positioned sub-apically. ${ }^{47}$ Thus, hyphal growth enables the organism to escape from a phagocyte, anchor within a cell layer or penetrate endothelia. ${ }^{2}$ Hyphal growth is also accompanied by the secretion of exoenzymes which participate in lysis of the substrate or may be involved in synthesis of fungal cell wall. ${ }^{48,49}$

\section{Stage 4: Vascular Dissemination}

C. albicans is capable of causing bloodstream infections in humans which help in its translocation. Cells of $C$. albicans stimulate endothelial cells to take them up via endocytosis. Thus the uptake and subsequent damage of endothelial cells is promoted by hyphae and the expression of hyphal regulon. After being internalized, cells of $C$. al bicans damage the endothelial cells, which in turn aids in more cells of $C$. albicans traversing the endothelium. The mechanism for endothelial damage is somewhat similar to that whereby the hyphae escape phagocytosis. Filamentous growth within endothelial cells may allow escape and transcytosis of the endothelial cell layer by $\mathrm{C}$. albicans concomitant with endothelial cell damage. ${ }^{39}$

\section{OTHER VIRULENCE FACTORS}

\section{Adherance \& Adhesins}

The persistence of candida on mucosal surface requires fungal adhesion to epithelial cells. Candidial adhesion is a complex process and the following three types of interactions have been proposed: 50

1. Protein - Protein interactions in which a protein on Candidal surface recognizes a protein or peptide ligand on epithelial or endothelial cells

2. Lectin like interactions in which lectin like proteins present on the Candidal cell wall adheres terminal sugars of the cell surface glycoproteins of human host ${ }^{51}$

3. Incompletely defined interactions in which a known surface component of $C$. albicans attaches to epithelial or endothelial surfaces by an as yet unidentified ligand

Most of the adhesions identified to date are mannoprotein and for individual adhesins, both protein and or carbohydrate portions have been implicated in adherence. ${ }^{40}$

\section{Phenotypic Switching:}

Besides the dimorphic transition from yeast to hyphae, C. al bicans is al so capable of a different form of morphologic change known as 'phenotypic switching' which is readily observed in the morphology of colonies. ${ }^{52,53}$

Two examples of phenotypic switching have been described in $\mathrm{C}$. albicans: the white-opaque transition and 3153A-type switching. In the whiteopaque transition, first described in the strain WO1 , cells switch between a form that gives rise to hemispherical, creamy white col onies (white phase) and a form that produces flat, gray col onies (opaque phase). ${ }^{54,55}$ The difference between white and opaque colonies reflects a dramatic difference in the appearance of individual cells. While cells in a white col ony are relatively round (comparable in shape to those of S.cerevisiae cells), those isolated from an opaque colony are elongated, asymmetrical and show surface pimples. ${ }^{53}$

The other switching system, 3153A-type switching, was described in cultures of the standard laboratory strain 3153A, and it has also been observed in other laboratory strains and clinical isolates. ${ }^{56-58}$ Distinct from the white- opaque transition, this type of switching produces at least seven different colony morphologies. The predominant colony type in this phenotypic strain is 'smooth', but variant colonies arise at a frequency 
of $\sim 10^{-4}$. These variant colony morphologies reflect, at least in part, the combination of the three main cellular forms of C. albicans cells (blastospores, pseudo-hyphal and hyphal cells) found in the colony dome, although the exact relationship between the colony morphology and the cellular forms that comprise it is not known. ${ }^{56,59}$

Switching can be triggered by low doses of UV radiation and after being triggered into the "high frequency switching mode', $\mathrm{C}$. al bicans exhibits high rates of alteration in colony morphology. ${ }^{3}$

The extraordinarily high frequency and reversibility of switching, the distinct phenotypes in the two switching systems, the developmental differences in hyphal formation and the differences in sensitivity to antifungal agents all suggest that switching systems have a role in pathogenesis. The pathogenic mechanisms of Candida which may be potentiated by switching mechanisms include the capacity to:

1. Invade and proliferate in extremely different body environments

2. Elude immune system by alterations in surface antigenicity

3. Escape antifungal treatment.

Switching may also selectively enhance the adhesion to oral mucosa, tissue penetration and secretion of enzymes such as proteinases and phospholipases. ${ }^{3}$

\section{Extracellular Hydrolytic Enzymes}

In susceptible hosts, C. albicans enters the bloodstream and causes deep seated infection in target organs. One factor that contributes to the process of virulence is hydrolytic enzyme production, which is known to play a central role in the pathogenicity of $\mathrm{C}$. albicans. Two types of secreted enzyme seem to be the most important: phosphol ipases and secreted aspartyl proteinases. ${ }^{60}$. 61

\section{Secreted Aspartyl Proteinases}

The extracellular proteolytic activity of C. albicans was discovered by Staib (1965), who was also the first to suggest a role for candid proteinasses in the pathogenesis of candidiasis. ${ }^{3}$ Evidence of a role of candida proteinase in the pathogenesis of candidiasis was briefly reviewed by Odds(1985). ${ }^{3}$ In a study done by MacDonals and Odds (1983), it was found that chemically induces mutant strains of $C$. al bicans, which showed low proteolytic activity were less virulent in mice than the strongly proteoltyic parental strains. These results were confirmed by Kwon - Chung et al (1985) and they also showed that revertants with restored proteolytic activity also regained their virulence. ${ }^{3}$

Secreted Aspatyl proteinases are known to degrade many human proteins, including mucin, extracellular matrix proteins, numerous immune system molecules, endothelial cell proteins, and coagulation and clotting factors. Therefore, the action of Sap proteins could be involved in all four stages of infection and probably greatly enhances the pathogenic ability of C. albicans. ${ }^{22}$

\section{Lipases:}

Lipolytic activity of Candida species was first described by Werner (1966), who recognized such activity amongst strains of $\mathrm{C}$. albicans, $\mathrm{C}$. stellatoidea and C. tropicalis. The lipolytic activity of $C$. al bicans was differentiated into phospholipase A and lysophospholipase by Price and Cawson 1977. Phospholipase production in C. albicans is limited to acidic growth conditions (ph 3.6 - 4.7) and is inversely proportional to the concentration of glucose and galactose in the media. ${ }^{3}$ Phospholipases are most likely to contribute to the pathogenicity of $C$. albicans by damaging host-cell membranes, which aids the fungus by facilitating invasion of host tissues. ${ }^{62}$

\section{Conclusion}

Candida species are ubiquitous fungi that represent the most common fungal pathogens that affect humans. The growing problem of mucosal and systemic candidiasis reflects the enormous increase in the number of patients at risk and the increased opportunity that exists for Candida species to invade tissues normally resistant to invasion.

The increased prevalence of local and systemic disease caused by Candida species has resulted in numerous new clinical syndromes, the expression of which depends primarily on the immune status of the host. The conversion of this relatively innocuous commensal organism to the pathogenic stage depends on an interaction between the organisms with the host environment and the resident bacteria present. Candida species also exhibit their own set of well-recognized virulence factors that may contribute to their ability to cause infection. 
Thus the exact nature of determinants of virulence in candida and the response of the host to these different virulence factors needs to be investigated further using recent advances in technol ogy.

\section{REFERENCES:}

1. Neville, Damm, Allen, Bouquot. Fungal and Protozoal Diseases. Texbook of Oral and Maxillofacial Pathology, $3^{\text {rd }}$ edition. Philadel phia. Saunders: An imprint of Elsevier Inc; 2009 pg 213-239.

2. Alexandra Brand. "Hyphal Growth in Human Fungal Pathogens and Its Role in Virulence," International J Microbio 2012.

3. Samarnayake L.P. Oral Candidosis. Edited by Lakshman P. Samarnayake and T. Wallace MacFarlane, $1^{\text {st }}$ edition. London 1990.

4. Han TL, Richard D Cannon, Silas G Villas-Boas. The Metabolic Basis of Candida Albicans Morphogenesis and Quorum Sensing. Fungal Gen Bio 2011; 48: 747-763.

5. Odds FC, Baillihre Tindall L Candida and candidosis. $2^{\text {nd }}$ ed, London: Baillihre Tindall 1988

6. Gloria Molero, Rosalia Diez-Orejas, Federico NavarroGarcia, Lucia Monteoliva, J esus Pla, Concha Gil, et. al. Candida albicans: Genetics, Dimorphism And Pathogenicity, Internatl Microbiol 1998; 1:95-106.

7. Saville, SP, Lazzell AL, Monteagudo C, Lopez-Ribot J L. Engineered control of cell morphology in vivo reveals distinct roles for yeast and filamentous forms of Candida albicans during infection. Eukaryotic Cell 2003; 1053-1060.

8. Bendel CM, Hess DJ, Garni RM, Henry-Stanley M, Wells $\mathrm{CL}$. Comparative virulence of Candida albicans yeast and filamentous forms in orally and intravenously inoculated mice. Critical Care Medicine 2003; 31: 501-507.

9. Grubb SEW, Murdoch C, Sudbery PE, Saville SP, LopezRibot J L, Thornhill MH. Adhesion of Candida albicans to endothelial cells under physiological conditions of flow. Infection and Immunity 2009; 77: 3872-3878.

10. Rooney PJ, Klein BS. Linking fungal morphogenesis with virulence. Cellular Microbiology 2002; 4: 127-137.

11. Fuqua WC, Winans SC, Greenberg EP. Quorum sensing in bacteria: the LuxR-Luxl family of cell density-responsive transcriptional regulators. J ournal of Bacteriology 1994; 176: $269-275$

12. Gray KM, Passador L, Iglewski BH, Greenberg EP. Interchangeability and specificity of components from the quorum-sensing regulatory systems of Vibrio fischeri and Pseudomonas aeruginosa. J Bacteriology 1994; 176: 30763080.

13. Hense BA, Kuttler C, Muller J , Rothballer M, Hartmann A, Kreft J U. Does efficiency sensing unify diffusion and quorum sensing? Nature Reviews Microbiology 2007; 5: 230-239.

14. Nealson $\mathrm{KH}$. Autoinduction of bacterial Iuciferase. Occurrence, mechanism and significance. Archives of Microbiology 1977; 112: 73-79.

15. Rosenberg E, Keller KH, Dworkin M. Cell density dependent growth of Myxococcus xanthus on casein. J Bacteriology 1977; 129: 770-777.
16. Eberhard A. 1972. Inhibition and activation of bacterial luciferase synthesis. J ournal of Bacteriology 1972; 109: 1101-1105.

17. Eberhard A, Burlingame AL, Eberhard C, Kenyon GL, Nealson K.H, Oppenheimer NJ . Structural identification of autoinducer of Photobacterium fischeri luciferase. Biochemistry 1981; 20: 2444-2449

18. Piper KR, Beck Von Bodman S, Farrand SK. Conjugation factor of Agrobacterium tumefaciens regulates $\mathrm{Ti}$ plasmid transfer by autoinduction. Nature 1993; 362: 448-450.

19. Bainton NJ , Bycroft BW, Chhabra SR, Stead P, Gledhill L, Hill PJ , Rees, C.E.D, Winson MK, Salmond GPC, Stewart GSAB, Williams P. A general role for the lux autoinducer in bacterial cell signalling: control of antibiotic biosynthesis in Erwinia. Gene 1992; 116: 87-91.

20. Alem MAS, Oteef MDY, Flowers TH, Douglas LJ . Production of tyrosol by Candida albicans biofilms and its role in quorum sensing and biofilm development. Eukaryotic Cell 2006; 5: 1770-1779.

21. Hornby J M, J ensen EC, Lisec AD, Tasto J J, J ahnke B, Shoemaker R, Dussault $P$, Nickerson KW. Quorum sensing in the dimorphic fungus Candida albicans is mediated by farnesol. Applied Environ Microbiology 2001; 67: 2982-2992.

22. J ulian R Naglik, Stephen J Challacombe, Bernhard Hube. Candida albicans Secreted Aspartyl Proteinases in Virulence and Pathogenesis. Microbiology Molecular Biology Reviews 2003; 67(3): 400-428

23. Sherwood-Higham , Zhu WY, Devine CA, Gooday GW, Gow NAR, Gregory DW. "Helical growth of hyphae of Candida albicans,"J Medical Veterinary Mycology 1994; 32(6): 437445.

24. McKenzie CGJ , Koser U, Lewis LE et al. "Contribution of Candida al bicans cell wall components to recognition by and escape from murine macrophages," I nfection Immunity 2010; 78(4): 1650-1658.

25. Persat F, Noirey N, Diana J et al. "Binding of live conidia of Aspergillus fumigatus activates in vitro-generated human Langerhans cells via a lectin of galactomannan specificity," Clin Experimental Immunology 2003; 133(3): 370-377.

26. Staib $P$, Zaugg C, Mignon B et al. “Differential gene expression in the pathogenic dermatophyte Arthroderma benhamiaein vitro versus during infection. Microbiology 2010; 156(3): 884-895.

27. Mora-Montes HM, Netea MG, Ferwerda $G$ et al. "Recognition and blocking of innate immunity cells by Candida al bicans chitin," I nfection Immunity 2011; 79(5):1961-1970.

28. Cheng SC, van de Veerdonk FL, Lenardon $M$ et al. "The dectin-1/inflammasome pathway is responsible for the induction of protective T-helper 17 responses that discriminate between yeasts and hyphae of Candida albicans," J Leukocyte Biology 2011; 90(2): 357-366.

29. Bruns S, Kniemeyer $O$, Hasenberg $M$ et al. "Production of extracellular traps against Aspergillus fumigatus in vitro and in infected lung tissue is dependent on invading neutrophils and influenced by hydrophobin RodA," PLoS Pathogens 2010; 6(4): 1000873.

30. Said-Sadier N, Padilla E, Langsley G, Ojcius DM. "Aspergillus fumigatus stimulates the NLRP3 
inflammasome through a pathway requiring ROS production and the syk tyrosine kinase," PLoS ONE 2010; 5(4): 10008.

31. Hise AG, Tomalka J , Ganesan S et al. "An essential role for theNLRP 3 I nflammasome in host defense against the human fungal pathogen Candida albicans," Cell Host Microbe, 2009; 5(5): 487-497.

32. Ouyang W, Kolls J K, Zheng Y. "The biological functions of T Helper 17 cell effector cytokines in inflammation,". I mmunity 2008; 28(4): 454-467.

33. Alexandra Brand, Anjalee Vacharaksa, Catherine Bendel J ennifer Norton, Paula Haynes, Michelle Henry-Stanley et al. An Internal Polarity Landmark Is Important for Externally Induced Hyphal Behaviors in Candida al bicans. Eukaryotic Cell 2008; 7(4): 712-720.

34. Brand A, Lee KeunSook, Veses V, Gow NAR. Calcium homeostasis is required for contact-dependent helical and sinusoidal tip growth in Candida al bicans hyphae. Molecular Microbiology 2009; 71(5): 1155-1164.

35. Gow NAR, Perera THS, Sherwood-Higham J et al. "I nvestigation of touch-sensitive responses by hyphae of the human pathogenic fungus Candida albicans," Scanning Microscopy 1994; 8(3): 705-710.

36. Clarissa J Nobile, J eniel E Nett, David R Andes, Aaron P Mitchell. Function of Candida albicans adhesin Hwpl in Biofilm Formation. Eukaryotic Cell 2006; 5(10): 1604-1610.

37. Staab J F, Bradway SD, Fidel PL, Sundstrom P. Adhesive and mammalian transglutaminase substrate properties of Candida albicans Hwpl. Science 1999; 283:1535-1538.

38. Sundstrom P, Cutler J E, Staab J F. Reevaluation of the role of HWP 1 in systemic candi diasis by use of Candida al bicans strains with selectable marker URA 3 targeted to the ENO1 locus. I nfect I mmun 2002; 70: 3281-3283.

39. Kumamoto CA, Vinces MD. Contributions of hyphae and hypha-co-regulated genes to Candida albicans virulence. Cellular Microbiology 2005; 7:1546-1554.

40. Cannon RD, Chaffin WL. Oral Colonization by Candida Albicans. Critical Reviews in Oral Biology \& Medicine 1999 10: 359.

41. Al-Fattani MA, Douglas LJ . "Biofilm matrix of Candida albicans and Candida tropicalis: chemical composition and role in drug resistance,"J Medical Microbiology 2006; 55(8): 999-1008.

42. Walker TS, Tomlin KL, Worthen GS et al. "Enhanced Pseudomonas aeruginosa biofilm devel opment mediated by human neutrophils," I nfection I mmunity 2005; 73(6): 36933701.

43. Dongari-Bagtzoglou A, Kashleva $H$, Dwivedi $P$, Diaz $P$, Vasilakos J. "Characterization of mucosal Candida albicans biofilms," PLOS ONE 2009; 4(11): 7967.

44. Martins $M$, Uppuluri $P$, Thomas DP et al. "Presence of extracellularDNA in the Candida albicans biofilm matrix and its contribution to bi ofilms". Mycopathologia 2010; 323331.

45. Paramonova $E$, Krom BP, van derMei HC, Busscher $\mathrm{HJ}$, Sharma PK. "Hyphal content determines the compression strength of Candida albicans biofilms," Microbiology 2009; 155(6):1997-2003.

46. Gero Steinberg. Hyphal Growth: a Tale of Motors, Lipids, and the Spitzenkorper. Eukaryotic Cell 2007; 6(3):351-360.

47. Gow NAR, Gooday GW. "Vacuolation, branch production and linear growth of germ tubes of Candida albicans," J Gen Microbiology 1982; 128(9): 2195-2198.

48. Archer DB, Wood DA. Fungal exoenzymes. In N. A. R. Gow and G. M. Gadd (ed.), The growing fungus. Chapman and Hall, London, United Kingdom, 1995, pg 135-162.

49. Gooday GW. Cell walls, In N. A. R. Gow and G. M. Gadd (ed.). The growing fungus. Chapman and Hall, London, United Kingdom, 1995, pg 41-62.

50. Calderone RA, Braun PC. Adherence and receptor relationships of Candida albicans. Microbiol Rev 1991; 55:120.

51. Critchley IA, Douglas LJ. Role of glycosides as epithelial cell receptors for Candida albicans. J Gen. Microbiol 1987; 133:636-643.

52. Soll DR. High-frequency switching in Candida albicans. Clin.Microbiol Rev 1992; 5: 183-203.

53. Soll DR, Morrow B, Srikantha T. High-frequency phenotypic switching in Candida albicans. Trends Genet 1993; 9: 6164.

54. Slutsky B, Staebell M, Anderson J, Risen L, Pfaller M, Soll DR. 'White-opaque transition': a second high-frequency switching system in Candida al bicans.J Bacteriol 1987; 169, 189-197.

55. Rikkerink EHA, Magee BB, Magee PT. Opaque-white phenotype transition: a programmed morphological transition in Candida albicans. J Bacteriol 1988; 170: 895899.

56. Slutsky B, Buffo J, Soll DR. High-frequency switching of colony morphology in Candida al bicans. Science 1985; 230: 666-669.

57. Pomes R, Gil C, Nombela C. Genetic analysis of Candida albicans morphological mutants. J Gen Microbiol 1985; 131: 2107-2113

58. Soll DR, Langtimm CJ, McDowell J, Hicks J, Galask R. High-frequency switching in Candida strains isolated from vaginitis patients. J Clin Microbiol 1987; 25: 1611-1622.

59. Radford DR, Challacombe SJ, Walter J D. A scanning el ectronmicroscopy investigation of the structure of colonies of different morphologies produced by phenotypic switching of Candida albicans. J Med Microbiol 1994; 40: 416-423.

60. Ghannoum MA. Potential role of phospholipases in virulence and fungal pathogenesis. Clin Microbiol Rev 2000; 13: 122143

61. De Bernardis F, Sullivan PA, Cassone A. Aspartyl proteinases of Candida albicans and their role in pathogenicity. Med Mycol 2001; 39: 303-313

62. Annemarie Borst, Ad C. Fluit. High levels of hydrolytic enzymes secreted by Candida albicans isolates involved in respiratory infections.J Medical Microbiology 2003; 52: 971974. 